Tattva-Journal of Philosophy

2019, Vol. 11, No. 1, v-vii

ISSN 0975-332X | https:/ / doi.org/10.12726/tjp.21.0

\title{
Editorial
}

Tattva Journal of Philosophy seeks to facilitate critical study and indepth reflection and analysis of issues, problems and concerns of human life, in order to further the directions and transformations human society needs to evolve into. It targets philosophers, educational institutions, research centres, social scientists, policy makers and any individual interested in and committed to human welfare. This issue brings together five articles that ask critical questions pertaining to our conceptualisations of space, time, and self-knowledge among many others.

Tattva Journal of Philosophy is one of the few journals that have remained committed to sharing philosophical reflections in current times. When I as a teacher of literature and literary theory enter an undergraduate class and speak about philosophy, an uncanny silence fills the room. Upon further prodding, students start asking what is my degree on and why I am speaking about these to a student of literature. The questions situate the status of philosophy and its relevance in current times. Philosophy is disregarded as being irrelevant and abstract, institutions and universities are closing departments dealing with philosophy, and the few liberal arts colleges which focus on philosophy are constantly being asked to prove the worth of the course.

Contemporary degree courses and even the purpose of education is filled with a sense of developing skills, an urgency of closure, an almost fundamental sense of being committed to singular monolithic truths. At the same time, the Umwelt that people inhabit is becoming more complex and demanding. The youth is being asked to respond to situations unfamiliar to their pedagogic world. An example of this is the moral problem of pulling the trigger. The latter refers to an ethical and moral thought experiment, used by Philippa Foot, Judith Thomson among others. The experiment has been modified and analysed by several scholars. This presents a problem, schematically represented as the following: A train needs to pass through a track. However, in one track there is one person and in the other, there are more than one person standing. You are obligated to perform one action: you 
could either let the train pass over a greater number of people in one track or pull the lever or turn on a switch that would divert the train wherein it would kill one person. This thought experiment does two things. One, that it allows us to reconsider moral and ethical choices as binaries and forces us to take a decision wherein killing is inevitable.

This also posits an important dilemma: the individual without any experience of the socio-political and historical details is considering him/herself as deemed fit to decide on another person's life and subsequently debates whether killing one or more is ethical. Furthermore, an individual, in the urgency of the decision to kill one or more fails to reflect and therefore overlooks the possibility to challenge the thought experiment wherein the option of stopping the train itself is not included as a viable option.

The simple thought experiment, whether we decide to agree or disagree with the designing of it, does indeed help us face the urgency of moral and ethical dilemmas that we encounter in our daily lives. However, the latter analysis, more importantly, allows us to reflect on the questions that remain hidden in all of our choices. This is the relevance of philosophical reflection. When we disregard the importance of philosophy, we forget that philosophy is a tool of thought and logical reasoning. It teaches us how to think critically and ask questions and engage with the discourses logically. It helps us understand language and our world in diverse ways which need not overlap or substitute rather co-exist in dialectic, through and due to language. This issue is partly reflective of these ideas.

In the article titled, Left Bank Cinema: Memories of History and the Experience of Time by Bijoy Philip VG, the author uses the films Les Statues Meurrent Aussi by Resnais and Marker and Marker's Sans Soleil (Sunless, 1983) to elucidate few features of Left Bank cinema to reflect on two important aspects of human existence, temporality and memory. Using mental spaces and facial dispositif, he demonstrates how modernist techniques and post-modernist undertones weave narratives together. The affective and cognitive connotations of these films are used to unpack and destabilise the tag of the French New Wave to demonstrate the medley of filmmaking techniques and ideological representations. 
In the article titled, Pulverizing the Monopoly of Mind: Three Roles of the Body in Cognition by Akhil Kumar Singh, the author provides a comprehensive review of the state-of-art of embodied cognition. The author posits the observations made by scholars regarding embodiment as an alternative to the conventional understanding of brain process and their relation to cognition. In doing so, the author presents a tripartite model of the agent's body, whereby the body is responsible for generation, operation and distribution of cognitive processes. This approach reinstates the deeply embedded roles of the body and environment in cognitive functioning. In the third article, Ways of Being of Equipment: A Heideggerian Enquiry into Design Process by Honeylal Puthussery, the author presents a detailed conceptual deliberation on Heidegger's ideations of equipment. From an ontological analysis, the author presents the varied understanding of how an equipment, its locations, its relations with the environment, agent's body, and functionality motivates its presence in our everyday lives.

In the fourth article, Self-Knowledge: Based on Knowledge of the First Cause of Creation (Aristotle's Conception of the Soul), Leon Miller Tallinn provides a detailed analysis of Aristotle's idea of the soul by revisiting his ideas of self-knowledge and the first cause of creation. The author aims to demonstrate that his methods of considering both logical positivism and a harkening of the perennial wisdom help to resolve problems pertaining to three issues: dualism, materialism and scepticism. The article concludes with an analysis of Aristotle's conceptualisation of integral being by being primordially motivated by self-actualisation, drives to resolve contradictions for a fuller development. In the article, Heidegger on Rhetoric: An Existential Deconstruction of the Notion of Communication, the author, Deepak Pandiaraj provides an existential and phenomenological analysis of Aristotle's theory of rhetoric by using a conceptual and a case-study analysis of speaking and the film Blow-Up. We invite our readers to reflect, think, and ask questions in the true spirit of philosophy to keep the dialectic alive.

\section{Rolla Das}

Issue Editor 